\title{
Focus structure and the referential status of indefinite quantificational expressions ${ }^{*}$
}

\author{
Carsten Breul \\ Dortmund \\ carsten.breul@ruhr-uni-bochum.de
}

\section{Introduction}

Many authors who subscribe to some version of generative syntax account for the two readings of such sentences as ( $1 \mathrm{a})$ and (1b) in terms of LF-ambiguity. There is assumed to be covert quantifier raising (QR), which results in two distinct possibilities for the indefinite quantificational expressions involved to take scope over each other $(2 \mathrm{a}, \mathrm{b})$ (see e.g. Chierchia \& McConnell-Ginet 2000 [1990]: ch. 3, 9, Fanselow \& Felix 1993 [1987]: 192f., Haegeman \& Guéron 1999: 541, Heim \& Kratzer 1998: ch. 7, 8, Kamp \& Reyle 1993: 279f., 288f.): ${ }^{1}$

(1) a. Some publisher offended every linguist

b. Everyone saw someone

a. $\forall x \exists y[K(x, y)]$

b. $\quad \exists y \forall x[K(x, y)]^{2}$

In this paper, an alternative account is proposed which dispenses with the idea that there are different scope relations involved in the readings of such sentences as in (1) and, consequently, with $\mathrm{QR}$ as the syntactic operation to be assumed for generating the respective LFs. I argue that it is rather focus structure in connection with type semantic issues pertaining to the indefinite quantificational expressions involved which result in the different readings associated with such sentences as in (1). The approach is motivated by an observation which leads to the conclusion that (1a) is ambiguous while (1b) is vague. ${ }^{3}$ This observation is based on an application of Lakoff's (1970) classic so-

* I am grateful to N. Asher, D. Büring, J. Jacobs, T. Kiss, B. Partee, G. Rauh, T. Tappe, C. Umbach for comments, discussion, hints, advice and questions, and for food for thought in general to all the presenters of papers at the DGfS-Workshop on "Information structure and the referential status of indefinite expressions" (Leipzig 28 Feb - 3 Mar, 2001), where I presented a version of this paper.

The paper is submitted to a special issue of "Theoretical Linguistics", edited by Klaus von Heusinger and Kerstin Schwabe

I See also May 1990 [1977], where the QR account of (supposed) LF-ambiguities of the kind illustrated by (1) was introduced and studied in detail for the first time in generative grammar.

2 Authors differ with respect to logical notations when representing different scope relations. The notation I use in (2) is adopted from Chierchia \& McConnell-Ginet (2000 [1990]). Haegeman \& Guéron (1999: 541), for instance, use the more explicit notation below in representing the two readings of (2b) (similarly Kamp \& Reyle 1993: 279f., 288f.).

a. $A x(x=H) \rightarrow E y(y=H) \&(S x y)$

b. Ey $(y=H) \& A x(x=H) \rightarrow(S x y)$

3 That is, neither both are ambiguous, as the above mentioned authors seem to assume, nor both vague, as argued by Kempson \& Cormack (1981). 
test, which I briefly recapitulate and whose applicability in the relevant cases is discussed in the next section.

\section{Ambiguity vs. vagueness: A problem for the standard account of 'quantifier scope relations'}

Consider first how Keenan (1978: 172) explains the difference between vague and ambiguous sentences.

There are many easily-agreed-upon instances of ambiguous sentences, such as the flying planes can be dangerous ones. There are equally many clear cases of vagueness. Thus the man on the table is hurt is vague, not ambiguous, according as the man is Albanian or not. Note of course that the situations in which the man is, or is not, Albanian are quite distinct. But we feel that neither of these situations is talked about in the original sentence.

We shall propose then the following sufficient condition for a sentence to be judged vague, rather than ambiguous, in certain respects: A sentence $S$ is vague according as it describes distinct situations $a$ and $b$ if, on a natural occasion of its use, the speaker of the sentence does not have to know (or believe he knows, a distinction we will not continue to make) whether in fact $a$ or $b$ is the case. Thus we may naturally assert that the man on the table is hurt without having to know whether the man is Albanian or not, so the sentence is correctly judged to be vague in this respect.

On the other hand, in a normal assertion of the chickens are ready to eat the speaker is expected to know whether the chickens are ready to be eaten or rather are ready to dine. So this sentence does not satisfy our criterion of vagueness, and is more plausibly judged ambiguous. [...] All we are saying then is that if a speaker can remain indifferent between alternatives $a$ and $b$ and still meaningfully assert some sentence then the sentence is vague not ambiguous according as $a$ or $b$ obtains.

Thus, a speaker may make a true utterance by saying The man on the table is hurt in a number of possible worlds comprising the set of worlds in which the man on the table is Albanian and the set of worlds in which he is not Albanian. And a speaker may make a true utterance in saying The chickens are ready to eat in a number of possible worlds comprising the set of worlds in which the chickens are ready to be eaten and the set of worlds in which the chickens are ready to dine. In deciding whether the respective utterance is vague or ambiguous we probe into our - linguistic knowledge informed intuition as to whether the speaker ought to or need not be able to remove the indeterminacy concerning these different sets of possible worlds in which the utterance is true.

Lakoff's (1970) so-test is designed so as to sharpen our judgement of whether a speaker can remain indifferent (as Keenan says) with respect to differences between states of affairs which in isolation can all be referred to truthfully by using a given sentence-string. ${ }^{4}$ Lakoff considers clearly ambiguous sentences such as (3a) in comparison to clearly vague sentences such as (3b).

(3) a. Selma likes visiting relatives

b. Harry kicked Sam

\footnotetext{
4 "A sentence is an output of grammar, a triple complex of syntactic, semantic and phonological information. A sentence-string is an uninterpreted surface sentential sequence." (Kempson \& Cormack 1981: 302, n. 1.)
} 
The ambiguity of (3a) is obvious. (3b) is vague in that Harry could have kicked Sam with his left or his right foot, for example. Lakoff observes that adding and so does/did $X$ to $(3 \mathrm{a}, \mathrm{b})$, as in $(4 \mathrm{a}, \mathrm{b})$, results in a significant difference as to possible readings.

a. Selma likes visiting relatives and so does Sam

b. Harry kicked Sam and so did Pete

(4b) can be used to refer truthfully to the state of affairs where Harry kicked Sam with his left foot and Pete kicked Sam with his right foot. In contrast, (4a) cannot be used to refer truthfully to a state of affairs where Selma likes going to visit relatives and Sam hates going to visit relatives but likes relatives who are visiting. That is, it is possible to associate one of the vaguely different alternatives of interpretation with the first clause of (4b) and the other with the conjoined so-clause, but it is not possible to associate one of the ambiguously different alternatives of interpretation with the first clause of (4a) and the other with the conjoined so-clause. These are linguistic effects resulting from our knowledge of the lexical-syntactic structure of the sentences involved and the way they are semantically computed (which I assume is compositional).

This observation can be applied as a test for distinguishing ambiguous and vague sentences also in cases where, supposedly, different quantifier scope relations are involved. (Well-known objections to the applicability of the test in the relevant cases will be discussed shortly.) Consider a model in which there are three Roman and three Greek letters and three numbers. (5a) appropriately and truthfully describes the situation depicted by $(5 b)$.

a. Every Roman letter is mapped to some number, and so is every Greek letter

b.
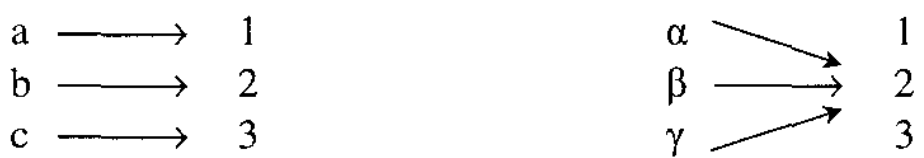

Thus, the clause Every Roman letter is mapped to some number, which is parallel to (1b) in the relevant respects, turns out to be vague rather than ambiguous. ${ }^{5}$ Vague readings are not to be distinguished by different LF-representations. Thus we have lost a motivation for assuming that sentences like (1b) are ambiguous between two truthconditionally distinct interpretations due to reversed quantifier scope relations represented along the lines of the logical formulae in (2). Consequently, we have also lost a motivation for postulating $\mathrm{QR}$, for it is the function of $\mathrm{QR}$ to attain different quantifier scope relations. In contrast to $(5 \mathrm{a})$, however, $(6 \mathrm{a})$ cannot be used to refer to (6b). So there seems to be genuine ambiguity involved in sentences such as (1a), to which Some Roman letter is mapped to every number is parallel in the crucial respects.

(6) a. Some Roman letter is mapped to every number, and so is some Greek letter

b.
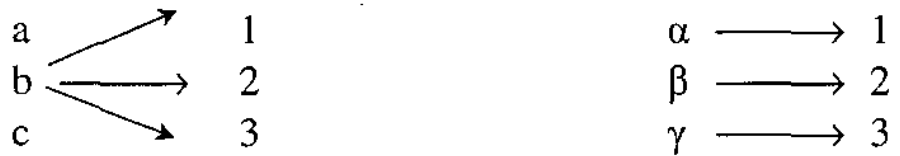

5 In a note, Hornstein (1995: 237f., n. 12) comes to the same conclusion with respect to the example Every man kissed a woman. In contrast to the approach taken in the present paper, Hornstein, although he aims at doing away with $\mathrm{QR}$ as well, still assumes that there are quantifier scope relations at issue in such sentences as in (1). 
It has been argued that the so-test cannot be applied in cases where one of the different readings entails the other, i.e. where the different readings stand in the relation of what Zwicky \& Sadock (1975) call "privative opposition". ${ }^{6}$ This is because "the existence of the more general understanding [i.e. the entailed one] guarantees that we will get all possible understandings" with the result that "we will always conclude that we are dealing with a lack of specification [i.e. 'vagueness']". (Ib.: 23.) Although true, this is no argument against what has been said above about ambiguity and vagueness with respect to sentences like (1a), (1b), Every Roman letter is mapped to some number and Some Roman letter is mapped to every number. For the claim that one reading of such sentences entails the other follows on the assumption that these readings correspond to the predicate calculus formulae of (2), for which it holds indeed that the $\exists \forall$-formula logically entails the $\forall \exists$-formula. However, it is my claim that the differences in reading between the respective sentences do not correspond to these formulae. Hence, there is no reason to assume a priori that in the semantics which is appropriate there holds an entailment relation between the respective readings as well. Moreover, if there was an entailment relation between the readings of the respective sentences, then we would expect to get vagueness as the result of the application of the so-test not only with sentences like (1b), i.e. those which exhibit the every-some order, but also with those like (1a), i.e. those which exhibit the some-every order. The fact that this is not the case, as shown by (6), proves that the so-test is indeed applicable in the cases in question.

I would like to present one more argument for the claim that sentences like (1a) are ambiguous while those like (1b) are vague. Imagine a situation in which various people tell you truthfully what is going on between a group of three girls, Mary Miller, Mary Hunt, and Mary Spencer, and a group of three boys, Peter Smith, Peter Jones, Peter Hill. A first communicator tells you that Peter Smith kissed Mary, another that Peter Jones kissed Mary, and a third that Peter Hill kissed Mary, without your having any idea about which Mary each communicator has in mind. Your utterance of (7) is appropriate and true with respect to the given domain of discourse, and nobody has the communicative right to expect from you that you are able to precisify what you mean by some girl (i.e. either 'some specific/singular girl' or 'some girl or other but not some specific/singular girl') ${ }^{7}$

Every boy kissed some girl

You cannot be said to equivocate in uttering (7), and you are fully justified in refusing to precisify along the lines just mentioned, for otherwise you would run the risk of saying something false. ${ }^{8}$ You are as justified in uttering (7) as the speaker from Keenan's passage above is justified in uttering The man on the table is hurt without knowing whether the man is Albanian or not.

Compare this situation with one in which a communicator tells you truthfully that Peter kissed Mary Miller, another that Peter kissed Mary Hunt, a third that Peter kissed Mary Spencer, without your having any idea about which Peter each communicator has in mind. Suppose now you uttered (8) with respect to the given domain of discourse.

6 See also Kempson \& Cormack 1981, for instance. Actually, this argument extends to the whole family of tests for ambiguity to which the so-test belongs (called "identity tests" by Zwicky \& Sadock).

7 On the notion of precisification and its relation to the vagueness/ambiguity distinction see Pinkal 1995 [1985], 1991.

8 Cf. Pinkal's (1995 [1985]: 100) criterion that "[p]ure vagueness is present when an indefinite expression does not allow natural precisifications." 
Of course, this utterance is also a true one. However, now I am justified in reproaching you with equivocation, i.e. with not being able to precisify what you mean by some boy although a felicitous utterance of (8) presupposes that you should be. ${ }^{9}$ You are in a communicatively infelicitous position parallel to that of a person who utters The chickens are ready to eat without knowing whether the chickens are ready to be eaten or whether the chickens are ready to dine (although to a much more subtle degree). In this case, you have no communicative right to remain indifferent as to the piece of knowledge whether some specific/singular boy or some boy or other but not some specific/singular boy kissed every girl. This difference between (7) and (8) supports the claim that the former is vague while the latter is ambiguous.

These intuitions might be felt to be delicate and subtle. Yet they are supported by much more robust intuitions about the 'behavior' of (7) and (8) under negation.

a. It is not true that every boy kissed some girl

b. It is not true that some boy kissed every girl

With respect to the first state of affairs, (9a) is clearly false irrespective of whether there was one specific Mary or some Mary or other who was kissed by every Peter. In contrast, we do not know which truth value to assign to $(9 b)$ with respect to the second state of affairs. In (9a), we are confronted with the negation of one sentence which (i.e. the negation) is false. In (9b), we are confronted with the negation of an ambiguous sentence-string which corresponds to one sentence which is false (some Peter or other kissed every Mary) and to a second sentence about which we do not have enough information to say if it is false or true (some specific Peter kissed every Mary). ${ }^{10}$

If we continue to think in terms of quantifier scope relations about the ambiguity involved here, then the problem is how to generate different scope relations for sentences like (1a) and block them for sentences like (1b). This may be done along the lines suggested by Hornstein (1995, 1999; see also fn. 5). As an alternative, I propose an account in terms of focus structure in connection with type semantic considerations which is not based on scope relations.

\section{Focus structure and its syntactic representation}

Let us assume that every representation of a root clause has either the general structure in (10a) or the one in (10b).

$$
\text { a. } \quad[\text { FocP } \alpha[\text { IP } \beta]]
$$

b. [IP $\alpha]$

with one of the three representations in (11) as possible realisations: ${ }^{11}$

9 Cf. Pinkal (1995 [1985]: 81): "Expressions that are ambiguous in the narrow sense require precisification."

10 I implicitly relegate the issue of vagueness and ambiguity to the lexical characteristics of some in this argumentation, which recalls that of Fodor \& Sag (1982). Indeed, as will become clear below, my account of the ambiguity of sentences like (8) in terms of focus structure is closely linked to one in terms of the lexical ambiguity of some. The point of my approach is that this lexical ambiguity is exploited differently in sentences like (8) as compared to those like (7).

11 In my presentation of the paper at DGfS 2001, I assumed that in thetic sentences there is a FocP as well and that the whole IP moves to spec-Foc. For syntactic reasons which are of no interest in the present context, I have abandoned this assumption. Nothing of significance for the semantic questions addressed here follows from this modification. 
(11)

predicate focus

categorical

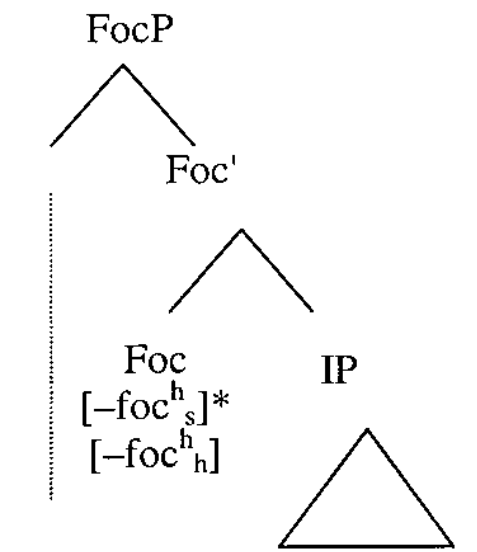

$X P_{i}$

$\left[- \text { foc }_{h}{ }_{h}\right]^{*}$ argument focus

identificational

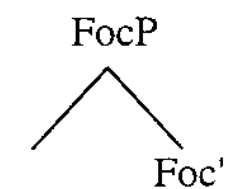

Foc'
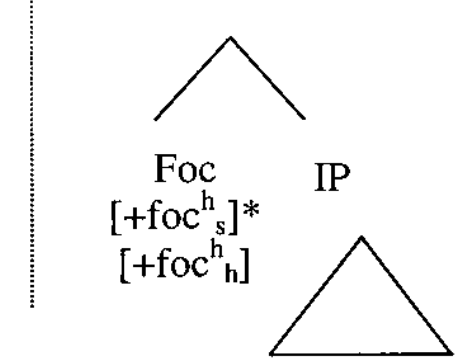

(..) $t_{\mathrm{i}}(\ldots)$ sentence focus

thetic

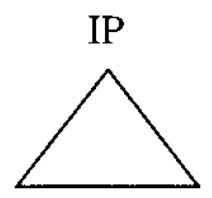

The concepts of predicate focus, argument focus and sentence focus structures are taken from Lambrecht (1994). In his theory, focus structure is defined in relation to a specific kind of presupposition, the so-called relevance presupposition, of which there are three types, each being associated with one of the three focus structure types.

The relevance presupposition associated with predicate focus structure determines the relevance of the respective utterance as providing relevant predicative information about a discourse entity under discussion, that is, about a topic. (12) provides a discourse fragment which illustrates a predicate focus utterance in A's reply, with my car or the pronoun it being the topic expression. (Small capitalisation here and in the examples below signifies a nuclear pitch accent on the respective word; a falling pitch accent would be appropriate.)

predicate focus structure

Q: What happened to your car?

A: My car/It broke DowN.

(from Lambrecht 1994: 223)

A sentence with predicate focus structure corresponds to a categorical sentence from the well-known thetic/categorical distinction (see e.g. Sasse 1987, Drubig 1992, Lambrecht 1994: pass.).

The relevance presupposition associated with argument focus structure determines the relevance of the respective utterance as providing the missing information in a relevant, variable containing, that is, open proposition. (13) provides an illustrating discourse fragment. $X$ broke down is the relevant open proposition, and the phrase $m y$ car in A's reply, which is both an information-structural argument ${ }^{12}$ and identificational focus expression, provides an identificational constant for the variable $x .^{13}$

12 It should be noted that the "word 'argument' in 'argument focus' is used here as a cover term for any non-predicating expression in a proposition, i.e. it includes terms expressing place, time, and manner. It is neutral with respect to the issue of the valence of predicates ('subcategorization') and the argument-adjunct distinction." (Lambrecht 1994: 224.)

13 For É. Kiss (1998), who distinguishes informational from identificational foci, the latter must be exhaustive. This is not necessarily the case for Lambrecht (1994: 122f.). I follow Lambrecht without further discussion. 
argument focus structure

Q: $\quad$ I heard your motorcycle broke down?

A: $\quad$ My CAR broke down.

(from Lambrecht 1994: 223)

A sentence with argument focus structure is also called identificational by Lambrecht (1994).

The relevance presupposition associated with sentence focus structure is zero. This does of course not mean that the utterance is irrelevant nor that it is not associated with any presuppositions. It means that there is neither a topic nor an open proposition in relation to which the respective utterance is relevant. An illustration is given in (14).

$$
\begin{aligned}
& \text { sentence focus structure } \\
& \text { Q: What happened? } \\
& \text { A: } \quad \text { My CAR broke down. }
\end{aligned}
$$

(from Lambrecht 1994: 223)

I conceive of a relevance presupposition as an assumption held by the speaker which belongs to the context of an utterance and which, just like any other presupposition, is essential for an assertive utterance to be or not to be truth-evaluable. ${ }^{14}$ Associating an inappropriate type of relevance presupposition with such an utterance results in its failure to be truth-evaluable.

I will use the categorical/identificational/thetic terminology in the following, replacing Lambrecht's (1994) predicate focus structure with categorical focus structure, argument focus structure with identificational focus structure, and sentence focus structure with thetic focus structure. On the one hand, this is because the thetic/categorical terminology and distinction is older and more widely known. On the other hand, I have made the experience that especially the terms 'predicate focus' and 'argument focus' tend to produce confusion. However, I adhere to Lambrecht's threefold distinction of focus structure types both with respect to his characterization of them in terms of different kinds of relevance presupposition and with respect to the idea that these three types - categorical, identificational, thetic - are the possible structural realization in an information-structural dimension called focus structure. ${ }^{15}$

I am assuming that focus structure is incorporated in syntax such that every root clause, and thus its derivation, manifests one of the three focus structure types. Root clauses (or sentences) in the traditional sense, which are focus structurally unspecified, have no theoretical status, that is, they do not exist in the theory proposed here.

The essential characteristic of the derivation of focus-structured root clauses - or, simply, root clauses - is the absence or presence of topic and focus features and consequently the absence or presence of phrase movement to the specifier position of a head Foc of a functional projection FocP (spec-Foc). In categorical and identificational sentences, there is movement to spec-Foc. The phrase which moves to spec-Foc carries a head feature $\left[ \pm f^{p} c_{h}\right.$ ] which is checked against the corresponding specifier feature $\left[ \pm \mathrm{foc}^{\mathrm{h}}{ }_{\mathrm{s}}\right]$ in the Foc-head such that both of them are erased (erasure being symbolized by the $\operatorname{star}(*)$ in the tree structures of (11)). The head feature $\left[ \pm f^{\circ} c_{h}^{h}\right]$ of the Foc-head is not erased. It is interpretable, that is, it has a semantic function and thus contributes to

14 On the role of presuppositions and context in general with respect to truth evaluability, see e.g. Chierchia \& McConnell-Ginet 2000 [1990]: ch. 6; as to the conception of 'context' as a set of assumptions, see Sperber \& Wilson 1995 [1986].

15 The other information-structural dimension has to do with the speaker's assumptions about the degrees of identifiability and activeness ('given/new') of discourse entities in the hearer's mind and the way these assumptions are lexical-syntactically reflected in sentences. 
the interpretation of the clause. ${ }^{16}$ If [-foc]-features are involved, we are confronted with categorical focus structure, and the phrase which moves to spec-Foc is a topic expression. If [+foc]-features are involved, we are confronted with identificational focus structure, and the phrase which moves to spec-Foc is an identificational focus expression. In a thetic sentence there are no $[ \pm f o c]-f e a t u r e s$, no FocP and thus no movement to spec-Foc.

For the limited purposes in this paper, I restrict myself to considerations of cases where nominal expressions move to spec-Foc. I call these nominal expressions 'DP', making no distinction between quantified and non-quantified nominal expression.

\section{The semantic function of the $[ \pm$ foc $]$-features}

In truth-functional semantics inspired by Montague (see Thomason (ed.) 1974, see also Heim \& Kratzer 1998), transitive verbs like offend and see as in (15) = (1) are commonly said to be of semantic type $<e,<e, t>>$.

(15) a. Some publisher offended every linguist

b. Everyone saw someone

If we take a flexible type in situ approach for the complement and the subject DPs with which such verbs combine semantically, we see that in principle these may be of three types:

$$
\begin{array}{rrl}
\text { a. } & \text { e } & \text { as object and subject } \\
\text { b. } & <<e,<e, t>>,<e, t>> & \text { as object } \\
\text { c. } & <<e, t>, t> & \text { as subject }
\end{array}
$$

The types given in $(16 \mathrm{~b}, \mathrm{c})$ correspond to the generalized quantifier interpretation of a subject or object DP, that is, an interpretation as a set of sets. While DPs like everyone or every publisher arguably have only the generalized quantifier interpretation, ${ }^{17}$ there are other DPs, including proper names, which are principally interpretable either as individuals, i.e. type e expressions, or as generalized quantifiers. ${ }^{18}$

Referential expressions can be identified with type e expressions. It is well known that indefinite quantificational DPs like someone or some publisher as in (15) above can be either referential or non-referential. That is, such DPs are principally type ambiguous between the three types mentioned in (16). This holds also for other kinds of indefinite quantificational DPs, such as a man or one man, but rarely, if ever, for DPs like everyone or every publisher (see fn. 17). Let us simplify matters and assume that for the

16 As to the checking mechanism see e.g. Radford 1997: ch. 5, towards which my sketch of [ \pm foc]feature checking is roughly oriented. Technically different and for syntax at large probably more appropriate accounts are available and still others imaginable. There should be no problem for anyone of them to accommodate movement of a phrase to the specifier position of some functional phrase with different semantic processing of that phrase depending on differences in the features responsible for the movement.

17 According to Partee (1987: 132), there are no e-type readings only for such DPs as are "most clearly 'quantificational': no man, no men, at most one man, few men, not every man, most men [but see also Partee's note 21 on most-DPs]. Every man could get an $e$-type reading [...] in case there is only one man; but linguistically it never seems to act as a singular 'referential' term".

18 As to the interpretation of proper names as generalized quantifiers, see e.g. Chierchia \& McConnellGinet 2000 [1990]: $512 \mathrm{f}$. 
latter the referential type e is principally ruled out. These, then, are lexical facts, ultimately determined by the lexical entries for the items some(one), every(one).

Let us assume that the $[ \pm$ foc]-features in the Foc-head determine the semantic types of the phrases in spec-Foc in the following way:

$$
\begin{array}{ll}
\text { a. } & {\left[- \text { foc }_{h}^{h}\right] \text { selects type e for a DP in spec-Foc. }} \\
\text { b. } & {\left[+ \text { foc }_{h}^{h}\right] \text { selects type }<<e, t>, t>\text { for a DP in spec-Foc. }}
\end{array}
$$

That DPs in spec-Foc of a [-foc]-head are of type e is supported by authors who claim that topic expressions are referential. ${ }^{19}$

If we apply the type selection mechanism in (17) to the examples in (15), we see that (15a) is threefold ambiguous, as shown in (18).

$$
\begin{aligned}
& \text { a. categorical: } \\
& \text { [FocP [Some publisher] } \text { Foc }_{[- \text {foc] }} \text { [IP } t \text { offended [every } \\
& \text { linguist } \left.\left.]_{<<e,<e, t>>,<e, t>>}\right]\right] \\
& \text { b. identificational: }
\end{aligned}
$$

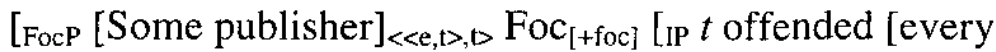

$$
\begin{aligned}
& \text { linguist } \left.\left.]_{<<e,<e, 1>>,<e, t>>}\right]\right] \\
& \text { c. thetic: }
\end{aligned}
$$

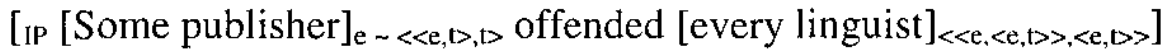

The subject some publisher may be in spec-Foc of a $[-f \circ c]$-head (categorical), or in spec-Foc of a [+foc]-head (identificational); or there are no $[ \pm f$ foc $]$-features and no FocP at all, and the type selection mechanism of (17) does not apply (thetic). In all three cases, the object every linguist is of type $\langle<\mathrm{e},\langle\mathrm{e}, \mathrm{t}\rangle\rangle,\langle\mathrm{e}, \mathrm{t}\rangle\rangle$, as type $\mathrm{e}$ is ruled out lexically. As regards the subject some publisher, it is of type e in the categorical case, of type $<<e, t>, t>$ in the identificational case, and in the thetic case, it is indeterminate between types $e$ and $<<e, t>, t>$, since its type has not been selected. (I represent indeterminateness or vagueness between types and interpretations by the tilde.) The interpretations of $(18 \mathrm{a}-\mathrm{c})$ in $\lambda$-notation are given in $(19 \mathrm{a}-\mathrm{c})$.

19 See e.g. Strawson 1971 [1964]: 97, Reinhart 1981: 65ff., Prince 1981: 251ff., 1984: 217f., Sasse 1987: 555, E. Kiss 1995: 7, Erteschik-Shir 1997: pass. As pointed out by J. Jacobs (in DGfS 2001 conference discussion), this raises the problem that an every-DP cannot be topic expression. How, then, can cases like the following be explained, where everybody in A's utterance seems to be a topic expression?

a. Q: Where did everybody go?

A: Everybody went home.

The only reason why we may think that everybody in $(\mathrm{aA})$ is a topic expression is that it appears in the context question, i.e. its denotation is given or 'active' in Lambrecht's (1994) sense. However, givenness/activeness of an expression's denotation/referent is no sufficient condition for its being a topic expression (see e.g. ib.: pass.). I would argue that (aA) is a thetic sentence and that, consequently, everybody is neither topic nor identificational focus expression. Note that a more natural utterance than $(\mathrm{aA})$ in the context of $(\mathrm{aQ})$ is (bi) below, which is derived from the identificational focus structure (bii) by a discourse or processing effort minimization rule which deletes everything but the identificational focus expression (cf. Sperber \& Wilson 1995 [1986]: 211).

b. i. Home.

ii. HOME, they went.

The slight unnaturalness of (aA) is due to the fact that a wh-question suggests an identificational sentence as answer, not a thetic one. But only a small amount of pragmatic inferencing is needed to achieve the required contextual effect (in the sense of Sperber \& Wilson 1995 [1986]) by uttering a thetic sentence instead of an identificational one in cases like this. 
(19) a. $\llbracket(18 \mathrm{a}) \rrbracket=\left[\lambda \mathrm{x}: \mathrm{x} \in \mathrm{D}_{\mathrm{e}} \cdot \mathrm{x}\right.$ offended every linguist $]$ (some publisher)

b. $\llbracket(18 b) \rrbracket=\left[\lambda x: x \in D_{<e, t>}\right.$. some publisher $\left.x\right]$ (offended every linguist)

c. $\quad \llbracket(18 \mathrm{c}) \rrbracket=\llbracket(18 \mathrm{a}) \rrbracket \sim \llbracket(18 \mathrm{~b}) \rrbracket$

In contrast to (15a), (15b) appears to be only twofold ambiguous, since the selection of type e for everyone in spec-Foc by a [-foc]-head and thus categorical focus structure is ruled out. As shown in (20), (15b) may have either thetic focus structure, or identificational focus structure with everyone in $\mathrm{spec}_{-\mathrm{Foc}}[+\mathrm{foc}]$, where the semantic type of the subject everyone is $<<\mathrm{e}, \mathrm{t}\rangle, \mathrm{t}\rangle$ and the object someone is indeterminate between types e and $<<e,<e, t>>,<e, t>>$.

(20) a. identificational focus structure:

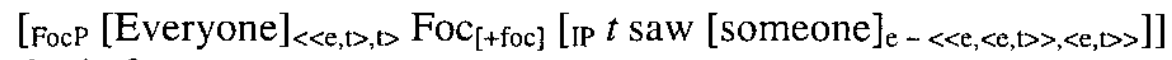

b. thetic focus structure:

$\left[\right.$ IP $[\text { Everyone }]_{<<e, t>, t>}$ saw $\left.[\text { someone }]_{\mathrm{e}} \sim<<e,\langle e, 1>>,<e, \downarrow)\right]$

Actually, (20a) and (20b) turn out to have identical, if vague, interpretations. The vagueness is due to the type indeterminacy of someone, which produces vagueness in the reading of the VP saw someone (see (21a)) and consequently in that of the whole clause (see (21b)).
a. $\llbracket$ saw someone $\rrbracket=$
$\left[\lambda \mathrm{x}: \mathrm{x} \in \mathrm{D}_{\mathrm{e}}\right.$. saw $\left.\mathrm{x}\right]$ (someone) $\sim\left[\lambda \mathrm{x}: \mathrm{x} \in \mathrm{D}_{<\mathrm{e},<\mathrm{e}, \mathrm{p}\rangle} . \mathrm{x}\right.$ someone $]$ (saw)
b. $\quad \llbracket(20 a) \rrbracket=\llbracket(20 b) \rrbracket=\left[\lambda x: x \in D_{<e, \downarrow}\right.$. everyone $\left.x\right]$ (saw someone)

The LF-difference between (20a) and (20b) is semantically conflated to (21b), which itself is vague in the way indicated.

\section{Taking stock: Focus structure instead of quantifier scope}

It is my claim that what has traditionally been analysed as an ambiguity in terms of the scopal relations between existential and universal quantifiers in sentences such as in (1) $=(15)$ is more appropriately captured by the focus structure differences just discussed.
a. Some publisher offended every linguist
b. Everyone saw someone

The truth-conditionally different interpretations of a sentence like (15a), which many authors have analyzed in terms of $\exists \forall$ vs. $\forall \exists$ quantifier scope relations, reflect the ambiguity between the categorical reading on the one hand and the identificational and thetic readings on the other hand. The intuition that there is a reading of (15a) in which the speaker has some specific publisher in mind of whom he predicates that he offended every linguist, without actually specifying the identity of this publisher (see Kamp \& Reyle 1993: 289f.), is represented as the categorical reading, where a [-foc]-head selects the referential type e denotation for the indefinite quantificational DP in specFoc. In contrast to $(15 \mathrm{a}),(15 \mathrm{~b})$ does not have a categorical reading. This corresponds to the fact that (15b) is ultimately not ambiguous at all, as we have seen. I would maintain that what linguists have in mind who consider sentences like (15b) to be ambiguous in terms of quantifier scope relations is rather the vagueness resulting from the type indeterminateness of the indefinite quantificational DP in object position. 


\section{On the structural ambiguity contributed by thetic focus structure}

Often it is possible to find states of affairs with respect to which one reading of an ambiguous sentence is true and the other false. Thus, with respect to the state of affairs depicted in (22a), the categorical clause $(22 b)$ is false while the identificational clause $(22 \mathrm{c})$ is true .

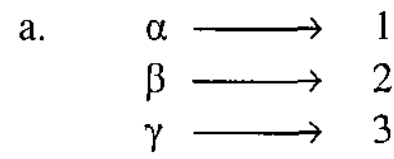

b. $\quad\left[\right.$ FocP $[\text { Some letter }]_{\mathrm{e}}$ Foc $_{[- \text {foc }]}[$ IP $t$ is mapped to [every number $\left.\left.]_{<<e,<e, t>>,<e, t>\rangle}\right]\right]$

c. $\quad\left[\right.$ FocP $[\text { Some letter] }]_{<<e, \downarrow, \downarrow)}$ Foc $_{[+ \text {foc }]}\left[{ }_{I P} t\right.$ is mapped to [every number] $\left.\left.]_{<<e,<e, \downarrow>,<e, \downarrow>}\right]\right]$

Indeed, this relation between states of affairs and linguistic expressions leads to the detection of structural ambiguity. But does this mean that, conversely, it should be possible to find ambiguity-sensitive states of affairs for every two structures that represent an ambiguity? I do not think so. While each truth-conditional difference in expressions using the same lexical material is reflected as a structural ambiguity in the syntax, there is, as far as I can see, no conceptual requirement that each case of structural ambiguity correspond to a difference in truth conditions. If this is correct, then there is no problem for my account when I concede that there is no state of affairs which is ambiguity-sensitive such that reference to it by a thetic sentence yields a truth evaluation not shared by any of the other corresponding sentences. ${ }^{20}$ In other words: If some thetic sentence $T$ has either a corresponding categorical or identificational sentence, as in (20), then $T$ shares its truth evaluation with the corresponding categorical or identificational sentence. If some thetic sentence $T$ has both corresponding categorical and identificational sentences, as in (18), then the truth evaluation of $T$ is identical to that of at least one of the two others. In still other words: Depending on whether a thetic sentence $T$ has one (categorical or identificational) or two (categorical and identificational) corresponding sentences, the set of truth conditions for $T$ is either identical to the set of truth conditions for the one corresponding sentence $\left(C_{\mathrm{T}}=C_{\mathrm{C} / 1}\right)$, or is the union of the sets of truth conditions for the two corresponding sentences $\left(C_{\mathrm{T}}=\right.$ $\left.C_{\mathrm{C}} \cup C_{\mathrm{I}}\right){ }^{22}$ Conversely, for categorical and identificational sentences which have a corresponding thetic sentence this means that the LF-difference existing between them does not correspond to a difference in truth conditions. Although LF-different, a thetic sentence does not differ truth conditionally from its corresponding categorical and/or identificational sentence(s).

20 In the present context I mean by 'corresponding sentences' those sentences which are not distinguished by the usual orthographical representation of a sentence-string, but which have different focus structures.

21 With $C_{\mathrm{T}}$ the set of truth conditions for a thetic sentence $T ; C_{\mathrm{C} I I}$ the set of truth conditions for either the corresponding categorical or identificational sentence.

22 With $C_{C}$ the set of truth conditions for the categorical and $C_{1}$ the set of truth conditions for the identificational sentence corresponding to $T$. 


\section{Implications and speculations}

The main objective of the present paper was to propose an account of the different readings of such sentences as in $(1)=(15)$ in terms of focus structure and type indeterminateness instead of the common quantifier scope explanation. However, the approach taken here implies that different focus structure types for sentence-strings have to be assumed not only for those cases where quantificational expressions in clausal subject and object positions are involved, but for all kinds of sentences. ${ }^{23}$ That is, every root clause (apart from those mentioned in fn. 23) has one of the three focus structure types derived by the syntactic mechanism explained in section 3 above and, in the categorical and identificational cases, is subject to the type selection mechanism postulated in (17) with attendant semantic implications and, possibly, truth conditional effects. I believe that this is indeed the case. For example, sentence-strings like those in (23) are indeed focus structurally ambiguous in the way indicated.

$$
\begin{aligned}
& \text { a. John is ill } \\
& \text { a'. categorical: } \quad\left[\text { FocP }\left[J_{O H n}\right]_{\mathrm{e}} \text { Foc }_{[- \text {foc }]}[\mathrm{IP} t \text { is ill }]_{<e, t>}\right] \\
& \text { a". identificational: [FocP } \left.[\mathrm{John}]_{<<e, t, t>} \mathrm{Foc}_{[+ \text {foc }]}[\text { IPP } t \text { is ill] }]_{<e, t>}\right] \\
& \left.\mathrm{a}^{\prime \prime \prime} \text {. thetic: [IP }[\text { John }]_{\mathrm{e} \sim<<, \mathrm{t}, \mathrm{l}>}[\text { is ill }]_{<\mathrm{e}, \mathrm{t})}\right] \\
& \text { b. Somebody is ill } \\
& \text { b'. categorical: [FocP } \left.[\text { Somebody }]_{\mathrm{e}} \text { Foc }_{[-f o c]}[\text { [P } t \text { is ill }]_{<e, t>}\right] \\
& \text { b". identificational: }\left[F_{F o c P}[\text { Somebody }]_{<<, t>, D} \text { Foc }_{[+f o c]}\left[I_{P} t \text { is ill }\right]_{<e, t>}\right] \\
& \mathrm{b}^{\prime \prime \prime} \text {. thetic: } \quad\left[\mathrm{IP}[\text { Somebody }]_{\mathrm{e} \sim<<, t>, \triangleright}[\text { is ill }]_{<e, \mathrm{l}}\right] \\
& \text { c. Everybody is ill } \\
& \text { c'. identificational: [FocP } \left.[\text { Everybody }]_{<<e, 1>, D} \text { Foc }_{[+f \circ c]}[\text { IP } t \text { is ill }]_{<e, t>}\right] \\
& \text { c". thetic: } \quad\left[\mathrm{IP}[\text { Everybody }]_{<<e, t, t>}[\text { is } i 11]_{<e, t>}\right]
\end{aligned}
$$

The point is that we do not always experience truth-conditional effects with these ambiguities. We do not experience truth-conditional effects between (23a') and (23a"), for instance. On the one hand, this is because the distinction between the individual John and the set of sets to which John belongs is truth-conditionally irrelevant ${ }^{24}$ although not semantic-computationally irrelevant, for the direction of functional application is different between (23a') and (23a"). ${ }^{25}$ On the other hand, the circumstances in which each of them can be appropriately uttered are disjoint. And this is because their relevance presuppositions (see above, sect. 3) are different, namely 'John is a topic for comment $x$ ' in the categorical case and ' $x$ is ill' in the identificational case. ${ }^{26}$

23 Except some kinds of thetic sentences like weather sentences (It's raining) or expletive theresentences (There was once a king), where we know from the presence of an expletive in initial position that they can neither be categorical nor identificational, as expletives can neither be topic nor identificational focus expressions. On expletive there-sentences as thetic sentences see also Drubig 1992: 167, pass.

24 This does not seem to be the case with indefinite quantificational expressions like somebody as in (23b), where the categorical reading with e-type (referential) somebody may be argued to differ truth conditionally from the identificational reading with $<<e, t>, t>-t y p e$ (quantificational) somebody.

25. In (23c), there are no differences in the semantic type of everybody nor, consequently, differences in the direction of functional application between the identificational and the thetic reading. Hence we get semantic conflation of syntactically different structures.

26 Note that this difference has an intonational reflex in that John will carry the nuclear pitch accent in the identificational sentence and no nuclear pitch accent in the categorical sentence. 
But, of course, the relevance presuppositions of categorical, identificational and thetic sentences are always different, and thus the circumstances in which they can be appropriately uttered are always disjoint. Does it make (more than trivial) sense to compare the truth conditions of sentences which can never be uttered in the same circumstances? If the answer is no, as I am inclined to believe, then the general truthconditional neutrality of thetic focus structure with respect to the corresponding categorical and/or identificational sentence and the truth-conditional neutrality of categorical and identificational sentences in cases like (23a') vs. (23a") may turn out to be a meaningless construct we can do away with. The most appropriate way of viewing the relation between focus structured sentences, truth conditions and relevance presuppositions may then be this: Every (focus structured) sentence has its own set of appropriateness conditions of use restricted (among other things) by its relevance presupposition; the set of truth conditions is relativized to the set of appropriateness conditions.

\section{Conclusion and outlook}

In this paper I have discussed an alternative approach to the analysis of one simple type of sentences involving indefinite quantificational expressions for which ambiguities in terms of quantifier scope variations have traditionally been assumed. Such sentences and their different readings have been used to motivate the syntactic operation of quantifier raising at $\mathrm{LF}(\mathrm{QR})$. That is, $\mathrm{QR}$ has been invented in order to derive the different quantifier scope relations that we find in predicate calculus formulae of the $\exists \forall / \forall \exists$-type, which supposedly represent the different readings of such sentences. It has been argued that these logical formulae do not adequately express the differences in interpretation of such examples and that an account in terms of focus structure and type semantic considerations is more appropriate. In this analysis of the respective examples there is no need for $\mathrm{QR}$.

The reader will rightly guess that I am dreaming of being able to dispense with both the quantifier scope hypothesis and the $\mathrm{QR}$ mechanism in all the other relevant examples as well. An attempt at the realization of such a dream will require much more work, a project which cannot be launched here. However, in response to a question raised by a commentator, ${ }^{27}$ I would like to address the case of so-called inverse linking phenomena in the Appendix.

\section{Appendix: Some remarks on inverse linking phenomena}

'Inverse linking' refers to those examples where the reading in which a lower quantificational expression seems to take scope over a higher quantificational expression is the only one possible or at least the strongly preferred one (see e.g. May 1990 [1977]: 61ff., 1985: pass., Heim \& Kratzer 1998: 197f., 221ff., 233ff.). The following are two cases in point.

\footnotetext{
a. categorical: John is ILL

b. identificational: JOHN is ill

27 In the discussion of my paper at DGfS 2001.
} 
(24) a. One apple in every basket is rotten (from Heim \& Kratzer 1998: 197)

b. Somebody from every city despises it (from May 1985: 68)

The inversely linked readings of $(24 a, b)$ are the salient, most natural ones: In every basket there is one apple which is rotten; every city has at least one citizen who despises the city of which he/she is a citizen. The point of these examples is that $\mathrm{QR}$ of the embedded every-DP seems to account straightforwardly both for the type-semantic issues involved in the semantic composition of the sentences (see Heim \& Kratzer 1998: 197f. with respect to (24a)) and for the fact that the pronoun it in (24b) can be bound by every city (which it has to in the relevant reading) given standard assumptions about binding in terms of standard c-command (see ib.: 234f.). ${ }^{28}$ As to the question of how the problem of binding may be solved in an approach in which there is no $Q R$ at all, see Hornstein (1995: 106ff., 118ff.) for various suggestions. I would like to go into some more detail about the type-semantic issue addressed by Heim \& Kratzer (1998: 197) with respect to $(24 a)$.

Heim \& Kratzer (1998: 197f.) present an attempt at a flexible type in situ analysis which fails. The essential passage is the following (ib.):

'in' has the same type of meaning as a transitive verb, <e,et $>$. So 'every' must have its type $<$ et, $<<e, e t>, e t>>$ meaning here. Thus we get:

【in every basket $\rrbracket=\lambda x$. for every basket $y, x$ is in $y$

We proceed to the next node up by Predicate Modification and get:

[apple in every basket $\rrbracket=\lambda \mathrm{x} . \mathrm{x}$ is an apple and for every basket $\mathrm{y}, \mathrm{x}$ is in $\mathrm{y}$

Of course, combining the denotation of apple with that of in every basket by Predicate Modification will result in nothing but the non-salient (perhaps impossible) reading where there is one single apple which is in every basket and which is rotten. The analysis fails since Heim \& Kratzer assume a single, rigid type for in here (but see ib.: 66f. and fn. 33 below) while allowing a flexible type only for every. However, there is no reason to assume that there is only one possible semantic type for a preposition like in. To assume type $\langle\mathrm{e},\langle\mathrm{e}, \mathrm{t}\rangle\rangle$ for in and to use Predicate Modification, as Heim \& Kratzer do in the above passage, is only justified if in is a lexical preposition. ${ }^{29}$ Yet, in every basket within the DP one apple in every basket in the salient reading of (24a) does not seem to be a lexical PP. If it were one, then in every basket would denote a local space, and it would be possible to substitute the locative deictic pro-form there for it under preservation of meaning. ${ }^{30}$ This is not possible, as the infelicity of (25B) suggests.

A: One apple in every basket was rotten.

B: Yes, you're right. \#One apple there was rotten.

Which semantic type does this 'non-lexical' in have? $?^{31}$

28 More precisely, it is $\mathrm{QR}$ in the form of adjunction to IP that allows for straightforward; standard, binding of the pronoun. In view of the problem that LF-extraction of every city from the subject violates a syntactic island condition, May (1985: 68f.) proposes an alternative to his 1977 analysis in which the embedded quantified expression does not adjoin by QR to IP but to its own containing DP. With an accordingly adjusted definition of c-command the configuration necessary for binding the pronoun is achieved.

29 See Rauh (e.g. 1995, 1996, 1997a, 1997b) on lexical, grammatical and governed prepositions.

30 Thanks to G. Rauh for pointing this out to me.

31 I call it 'non-lexical' for brevity's sake here. In more cautious terms, it is at least not a typical lexical preposition. Nor is it a grammatical or governed preposition in Rauh's (1995, 1996, 1997a, 1997b) sense. 
The syntactic bracketing of the DP one apple in every basket, reduced to the essentials for purposes of semantic composition, is this:

\section{[one [apple [in [every [basket]]]]]}

Obviously, (25) in the salient reading of (24a), where it is subject, cannot be of type e, which leaves the generalized quantifier denotation $<<e, t>, t>$ for it. For the quantificational determiner one we need that one of its alternative types which yields $<<e, t>, t>$ when combined, i.e. $<<e, t>,<<e, t>, t>>$ (cf. Heim \& Kratzer 1998: 207, n. 26) ${ }^{32}$ Consequently, the NP [apple [in [every [basket]]]] is of type $<\mathrm{e}, \mathrm{t}>$, that is, of the common noun type, just like apple. The PP in every basket, then, has to be combined with $<\mathrm{e}, \mathrm{t}\rangle$-type apple so as to result in $<\mathrm{e}, \mathrm{t}>$-type apple in every basket. This means that the PP in every basket has to be of type $\langle<\mathrm{e}, \mathrm{t}\rangle,\langle\mathrm{e}, \mathrm{t}\rangle\rangle$. Every basket being either of type $<<e, t>, t>$ or of type $<<e,<e, t>>,<e, t>>$, it follows that the type of in is either $<<<e, t>, t>,<<e, t>,<e, t>>>$ or $<<<e,<e, t>>,<e, t>>,<<e, t>,<e, t>>>{ }^{33}$

one apple in every basket $/<<e, t>, t>$

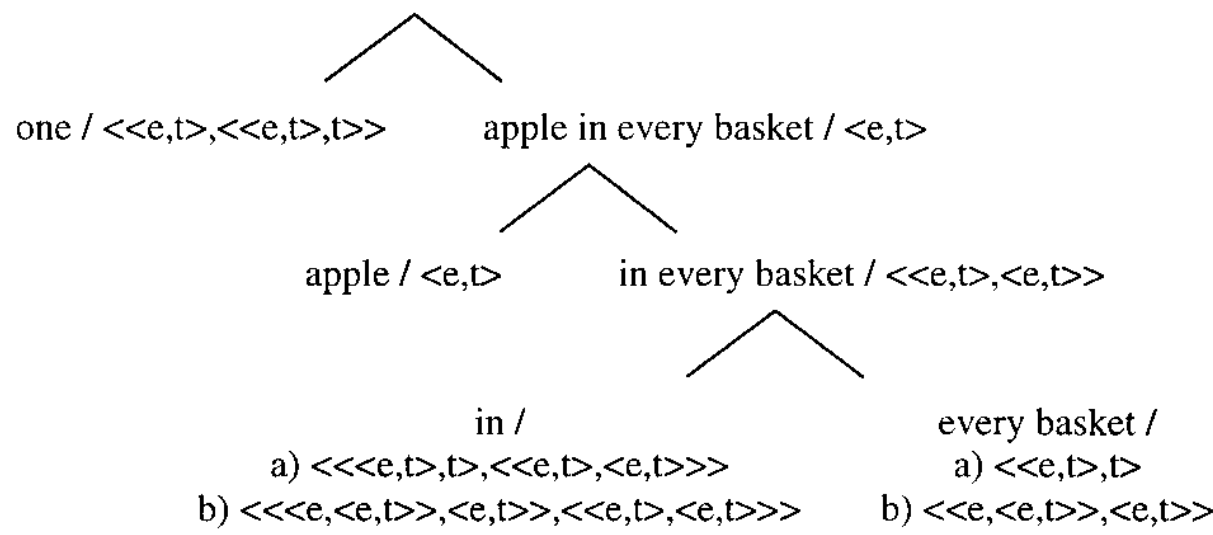

In sum, a QR-less analysis of inverse linking sentences like (24a) does not pose any type semantic problems if we take into account that in here is not a typical lexical preposition and thus not of type $<\mathrm{e},<\mathrm{e}, \mathrm{t}>>$. This analysis undermines Heim \& Kratzer's (1998) suggestion that one can hardly do without QR in view of sentences like (24a).

32 According to Heim \& Kratzer (1998: 182) every determiner is either of type $<<e, t>,<<e, t>, \mathrm{t}>$ or $<<e, t>,<<e,<e, t>>,<e, t>>>$. The latter is needed for DPs in object position.

33 The type for the PP in every basket just derived, $<<\mathrm{e}, \mathrm{t}\rangle,<\mathrm{e}, \mathrm{t}>>$, is that of the PP in Texas, which Heim \& Kratzer (1998: 66) assume in their discussion of a Functional Application (FA) alternative to their Predicate Modification (PM) analysis of this constituent. As they assume type e for Texas in this PP, it follows that they derive $<\mathrm{e},<<\mathrm{e}, \mathrm{t}\rangle,<\mathrm{e}, \mathrm{t} \gg\rangle>$ as the type for $i$. Note the systematic relationship between this type and the two possibilities given in (27) for in, such that all three types can be expressed in the

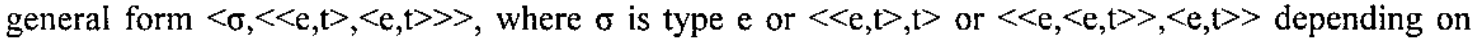
which of these the DP complement of the preposition has. It seems appropriate to work with PM (and the corresponding types) when confronted with lexical prepositions and with FA (and the corresponding types) when confronted with non-lexical prepositions. Operating by FA in the interpretation of non-lexical PPs may be an alternative to considering them as either semantically vacuous or as denoting "the identity function of the appropriate type" such that a PP like of John is

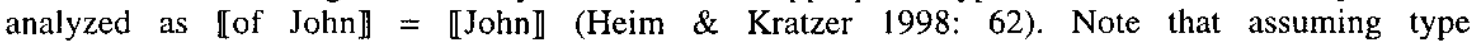
$<\mathrm{e},<<\mathrm{e}, \mathrm{t}\rangle,<\mathrm{e}, \mathrm{t}\rangle>>$ for of if combined with e-type John results in the PP of John of type $<<\mathrm{e}, \mathrm{t}\rangle,<\mathrm{e}, \mathrm{t}>>$, which can be combined with any type <e,t> expression, such as father or proud, for example, so as to result in another constituent of type <e,t $>$ (father/proud of John) - a satisfactory result. 


\section{References}

Chierchia, G.; McConnell-Ginet, S. (2000 [1990]): Meaning and Grammar: An Introduction to Semantics. 2nd edn. Cambridge (MA); London.

Drubig, H. B. (1992): Zur Frage der grammatischen Repräsentation thetischer und kategorischer Sätze. In: Jacobs, J. (ed.): Informationsstruktur und Grammatik. Opladen. 142-195.

É. Kiss, K. 1995. Discourse Configurational Languages: Introduction. In: É. Kiss, K. (ed.): Discourse Configurational Languages. New York; Oxford. 3-27.

É. Kiss, K. (1998): Identificational focus versus information focus. Language 74: 245-273.

Erteschik-Shir, N. (1997): The dynamics of focus structure. Cambridge.

Fanselow, G.; Felix, S. W. (1993 [1987]): Sprachtheorie: Eine Einführung in die Generative Grammatik. Vol. 2: Die Rektions- und Bindungstheorie. 3rd edn. Tübingen; Basel.

Fodor, J. D.; Sag, I. A. (1982): Referential and quantificational indefinites. Linguistics and Philosophy 5: 355-398.

Haegeman, L.; Guéron, J. (1999): English Grammar: A Generative Perspective. Oxford; Malden (MA).

Heim, I.; Kratzer, A. (1998): Semantics in Generative Grammar. Malden (MA) \& Oxford.

Hornstein, N. (1995): Logical Form: From GB to Minimalism. Oxford; Cambridge (USA).

Hornstein, N. (1999): Minimalism and Quantifier Raising. In: Hornstein, N.; Epstein, S. D. (eds.): Working Minimalism. Cambridge (MA); London. 45-75.

Kamp, H.; Reyle, U. (1993): From Discourse to Logic: Introduction to Modeltheoretic Semantics of Natural Language, Formal Logic and Discourse Representation Theory. Dordrecht; Boston; London.

Keenan, E. L. (1978): Some Logical Problerns in Translation. In: Guenthner, F.; Guenthner-Reutter, M. (eds.): Meaning and Translation: Philosophical and Linguistic Approaches. London. 157-189.

Kempson, R. M.; Cormack, A. (1981): Ambiguity and quantification. Linguistics and Philosophy 4: 259309.

Lakoff, G. (1970): A Note on Vagueness and Ambiguity. Linguistic Inquiry 1: 357-359.

Lambrecht, K. (1994): Information structure and sentence form: Topic, focus, and the mental representation of discourse referents. Cambridge.

May, R. C. (1990 [1977]): The Grammar of Quantification. New York; London.

May, R. (1985): Logical Form: Its Structure and Derivation. Cambridge (MA); London.

Partee, B. H. (1987): Noun Phrase Interpretation and Type-Shifting Principles. In: Groenendijk, J.; de Jongh, D.; Stokhof, M. (eds.): Studies in Discourse Representation Theory and the Theory of Generalized Quantifiers. Dordrecht; Providence. 115-143.

Pinkal, M. (1995 [1985]): Logic and Lexicon: The Semantics of the Indefinite [Logik und Lexikon: Die Semantik des Unbestimmiten]. Transl. Geoffrey Simmons. Dordrecht; Boston; London.

Pinkal, M. (1991): Vagheit und Ambiguität. In: von Stechow, A.; Wunderlich, D. (eds.): Semantics: An International Handbook of Contemporary Research. Berlin; New York. 250-269.

Prince, E. F. (1981): Topicalization, Focus-Movement, and Yiddish-Movement: A Pragmatic Differentiation. In: Alford, D. et al. (eds.): Proceedings of the Seventh Annual Meeting of the Berkeley Linguistics Society. Berkeley. 249-264.

Prince, E. F. (1984): Topicalization and Left-Dislocation: A Functional Analysis. In: White, S. J.; Teller, V. (eds.): Discourses in Reading and Linguistics. New York. 213-225.

Radford, A. (1997): Syntactic Theory and the Structure of English: A Minimalist Approach. Cambridge.

Rauh, G. (1995): Präpositionen und Rollen. Sprachwissenschaft 20: 123-167.

Rauh, G. (1996): Zur Struktur von Präpositionalphrasen im Englischen. Zeitschrift für Sprachwissenschaft 15: 178-230.

Rauh, G. (1997a): Englische Präpositionen zwischen lexikalischen und funktionalen Kategorien. In: Löbel, E.; Rauh, G. (eds.): Lexikalische Kategorien und Merkmale. Tübingen.

Rauh, G. (1997b): Lokale Präpositionen und referentielle Argumente. Linguistische Berichte 171: 415442.

Reinhart, T. (1981): Pragmatics and linguistics: An analysis of sentence topics. Philosophica 27: 53-93.

Sasse, H.-J. (1987): The thetic/categorical distinction revisited. Linguistics 25: 511-580.

Sperber, D.; Wilson, D. (1995 [1986]): Relevance: Communication and Cognition. 2nd edn. Oxford; Cambridge (MA).

Strawson, P. F. (1971 [1964]): Identifying reference and truth-values. In: Steinberg, D. D.; Jacobovits, L. A. (eds.): Semantics: An interdisciplinary reader in philosophy, linguistics and psychology. Cambridge. 86-99.

Thomason, R. H. (ed.) (1974): Formal Philosophy: Selected Papers by Richard Montague. New Haven; London.

Zwicky, A. M.; Sadock, J. M. (1975): Ambiguity tests and how to fail them. In: Kimball, J. P. (ed.): Syntax and Semantics. Vol. 4. New York; San Francisco; London. 1-36. 